\title{
Penetration of Toxoplasma gondii into Host Cells Induces Changes in the Distribution of the Mitochondria and the Endoplasmic Reticulum
}

\author{
Edésio José Tenorio de Melo, Técia Ulisses de carvalho and Wanderley de Souza* \\ Laboratório de Ultraestrutura Celular Hertha Meyer, Instituto de Bioflsica Carlos Chagas Filho, Universidade \\ Federal do Rio de Janeiro, Ilha do Fundäo, 21941, Rio de Janeiro, RJ, Brasil.
}

Key words: Toxoplasma gondii/parasite-host cell interaction/fluorescence microscopy/electron microscopy/mitochondria /endoplasmic reticulum/Golgi complex

\begin{abstract}
$A B S T R A C T$. Fluorescence microscopy, using dyes which specifically label mitochondria, endoplasmic reticulum and the Golgi complex, and transmission electron microscopy, were used to analyze the changes which occur in the organization of these structures during interaction of Toxoplasma gondii with host cells. In uninfected cells the mitochondria are long filamentous structures which radiate from the nuclear region toward the cell periphery. After parasite penetration they become shorter and tend to concentrate around the parasite-containing vacuole (parasitophorous vacuole) located in the cytoplasm of the host cell. The mitochondria of extracellular parasites, but not of those located within the parasitophorous vacuole, were also stained by rhodamine 123. Labeling with DiOC6, which binds to elements of the endoplasmic reticulum, in association with transmission electron microscopy, revealed a concentration of this structure around the parasitophorous vacuole. The membrane lining this vacuole was also stained, suggesting that components of the endoplasmic reticulum are also incorporated into this membrane. The Golgi complex, as revealed by staining with NBD-ceramide and electron microscopy, maintains its perinuclear position throughout the evolution of the intracellular parasitism.
\end{abstract}

Toxoplasma gondii is a parasitic protozoan able to infect a wide range of nucleated cells of the vertebrate host (12). It has been shown that it enters the host cell either by phagocytosis (2), or actively (18). The success of $T$. gondii tachyzoites as an intracellular parasite can be attributed to their unique capacity to enter the endocytic vacuole of both phagocytic and nonphagocytic cells and to block, by a mechanism as yet undefined, the fusion of host cell lysosomes with the parasite-containing endocytic vacuoles (12).

Once within a parasitophorous vacuole, $T$. gondii multiplies with a generation time of 5 to $10 \mathrm{~h}$, until the complete destruction of the host cell occurs (2). Very little is known about the influence of infection by $T$. gondii tachyzoites on the distribution of cytoplasmic structures of the host cell. It has been reported that host cell mitochondria accumulated around the parasitophorous vacuole, where the parasite grows and multiplies (11, 21).

In the last few years new fluorescent probes have been developed allowing examination in living cells, by fluorescence microscopy, the distribution of important cytoplasmic structures such as the mitochondria (6), the endoplasmic reticulum (8) and the Golgi complex (13). We decided to use these probes, as well as transmission elec-

\footnotetext{
* To whom all correspondence should be addressed.
}

tron microscopy, to analyze the fate of some organelles of the host cell during the development of $T$. gondii within its host cell. The results obtained are described in this paper.

\section{MATERIALS AND METHODS}

Parasites. Tachyzoites from the virulent $\mathrm{C}$ strain of Toxoplasma gondii (Supplied by Dr. Sergio Coutinho, Fundaçào Oswaldo Cruz, Rio de Janeiro, Brasil) were maintained by intraperitoneal passages in Swiss mice and were collected in Ringer's solution at $\mathrm{pH} 7.2,48-72 \mathrm{~h}$ after infection. The suspension of ascites fluid obtained from infected mice was centrifuged at $200 \mathrm{~g}$ for $7-10$ minutes at room temperature to remove cells and debris. The supernatant, which contained the parasites, was collected and centrifuged at $1,000 \mathrm{~g}$ for 7-10 minutes. The pellet obtained was washed 2 or 3 times with phosphate-buffered saline solution (PBS), $\mathrm{pH} 7.2$, and resuspended to a density of $10^{6}$ parasites $/ \mathrm{ml}$ in 199 medium without fetal calf serum. The parasites were used within $30-40$ minutes after removal from the mouse peritoneal cavity, and the viability was evaluated using a dye-exclusion test with Trypan blue.

The host cell. VERO cells (kidney fibroblast of African green monkey) were maintained in Falcon plastic flasks using 199 medium with $4 \%$ fetal calf serum and passed by trypsinization when the cell density approached a confluent monolayer. 
One day before use in the experiments, approximately $2 \times 10^{5}$ VERO cells were placed on Linbro tissue plates that contained a sterile coverslip, or were plated into $25 \mathrm{~cm}^{2}$ flasks $\left(3-5 \times 10^{5}\right.$ /flasks) and maintained at $37^{\circ} \mathrm{C}$ overnight in $5 \% \mathrm{CO}_{2}$.

Host cell parasite interaction. Parasites suspended in 199 medium were incubated for periods varying from 9 to $48 \mathrm{~h}$ at $37^{\circ} \mathrm{C}$ in the presence of the cell cultures at a parasite-cell ratio of $10: 1$. Afte $1 \mathrm{~h}$ incubation, the cells were washed twice with buffer to remove extracellular parasites and processed for fluorescence microscopy, or electron microscopy.

Fluorescence microscopy. For visualization of the mitochondria the purified laser dye rhodamine 123 (Eastman) was dissolved in dimethyl sulfoxide (DMSO) at a concentration of $1 \mathrm{mg} / \mathrm{ml}$ and subsequently diluted to $10 \mu \mathrm{g} / \mathrm{ml}$ in 199 medium (SIGMA). Cultured cells grown on $12 \mathrm{~mm}$-diameter glass coverslips without or with parasites were incubated with rhodamine $123(10 \mu \mathrm{g} / \mathrm{ml})$ for 30 minutes at $37^{\circ} \mathrm{C}$. Coverslips were then rinsed through three to five $\mathrm{ml}$ changes of medium and mounted in medium supplemented with $4 \%$ fetal calf serum. Labeled cells were examined by epifluorescent illumination of either $546 \mathrm{~nm}$ (rhodamine excitation) or $485 \mathrm{~nm}$ (fluorescein excitation) on a Zeiss Axioplan microscope equipped with a Zeiss planopochromat objective lens $(63 \times)$. Photographs were taken on Kodak Tri-X (Asa 400) or Kodak Ektachrome 400 (Asa 400) film using the automatic exposure control of the Zeiss camera to this microscope. Tri-X film was developed for 10 min in Kodak HC 110 (dilution B) and Ektachrome 400 was developed with Kodak E-6 processing.

For visualization of the endoplasmic reticulum DiOC6 (33'-dihexyloxacarbocyanine iodide) staining was employed. The cells grown on coverslips (control or infected) were fixed for 2-3 min at room temperature in $0.25 \%$ glutaraldehyde in $0.1 \mathrm{M}$ sodium cacodylate buffer, $\mathrm{pH} 7.4$. Cells were stained with $2.5 \mu \mathrm{g} / \mathrm{ml}$ of the fluorescent dye in cacodylate buffer for $30 \mathrm{sec}$ at room temperature. The coverslips, after being rinsed three times, were mounted as described above.

For visualization of the Golgi complex, C6-NBD-ceramide staining was used. The cells were cultivated as described above, washed in 199 medium without serum and incubated in a solution containing C6-NBD-ceramide plus bovine serum albumin (BSA) diluted in 199 medium without serum, for 10 minutes at $37^{\circ} \mathrm{C}$ (final concentration of $\mathrm{C} 6-\mathrm{NBD}$-ceramide was of $1.4 \mu \mathrm{M}$ ), washed 3 times with 199 medium without serum and incubated in this medium for 30 minutes at $37^{\circ} \mathrm{C}$, after which the cultures were twice washed in the medium, mounted and observed, as described above.

Electron microscopy. VERO cells were plated in culture flasks, cultivated as described above and allowed to interact with the parasites. After interaction the cultures were washed with PBS and fixed for $1 \mathrm{~h}$ at room temperature in a solution containing $1 \%$ glutaraldehyde, $4 \%$ paraformaldehyde, $5 \mathrm{mM}$ $\mathrm{CaCl}_{2}$ and $5 \%$ sucrose in $0.1 \mathrm{M}$ cacodylate buffer, $\mathrm{pH} 7.2$. Then, they were washed with cacodylate buffer with $5 \%$ sucrose and postfixed for $1 \mathrm{~h}$ in a solution containing $1 \% \mathrm{OsO}_{4}$, $0.8 \%$ potassium ferrocyanide and $5 \mathrm{mM} \mathrm{CaCl}_{2}$ in $0.1 \mathrm{M}$ caco- dylate buffer, $\mathrm{pH}$ 7.2. The cells were rinsed with cacodylate buffer, dehydrated in acetone and embedded in Epon. Thin sections were stained with uranyl acetate and lead citrate, and observed with a Zeiss 902 Electron Microscope.

\section{RESULTS}

Rhodamine 123 stain. Examination of living VERO cells by fluorescence microscopy after exposure to rhodamine 123 (methyl-O-(6-amino-3'-imino-3H-xanthen-9yl benzoate monohydrochloride) revealed that this dye was selectively accumulated in the mitochondria. In control cells, large filamentous mitochondria radiated from the perinuclear region toward the cell periphery (Figs. 1-2). After infection of the cell with tachyzoites of $T$. gondii, these filamentous mitochondria were concentrated around perinuclear and parasitophorous vacuoles that had parasites in the process of dividing (Figs. 3-5). After longer incubation times there was fragmentation of the mitochondria so that only short mitochondria were seen surrounding the parasitophorous vacuole (Figs. 4-5). However, the intensity of the fluorescence did not vary according to the parasite-host cell interaction time.

No fluorescence was seen in the intracellular parasites. However, those which remained adhered to the host cell surface were stained (Fig. 6).

DiOC6 stain. It has been reported that the lipophilic cationic fluorescent dye DiOC6 selectively stains mitochondria in living cells in response to the high mitochondrial membrane potential (6). However, when a higher concentration of the dye $(0.5$ to $2.5 \mu \mathrm{g} / \mathrm{ml})$ is used, other cellular membranes become visible (20), mainly those of the endoplasmic reticulum. Such staining is more evident when fixed cells are used.

Glutaraldehyde-fixed Vero cells incubated in the presence of DiOC6 showed a high fluorescence in the perinuclear region and a punctuated pattern of staining throughout the cytoplasm (Fig. 7). In some regions, especially at the periphery, a reticulated aspect was seen (Fig. 7).

Cell infection by $T$. gondii did not interfere with the general pattern of staining of the cells (Figs. 8-9, 1011). However, in infected cells a reticulated pattern of staining was frequently seen (Figs. 10-11). In micrographs where the focal plane was in the portion of the cytoplasm where the parasites are located, it was clear that the parasites were also stained (Figs. 12-13). It was also clear that the membrane lining the parasitophorous vacuole was also lightly stained (Fig. 13).

C6-NBD-ceramide stain. C6-NBD-ceramide was administered to cells as a complex with bovine serum albumin (C6-NBD-ceramide-BSA). This complex reliably labeled the Golgi complex of living cells. In the present study we observed that the Golgi complex stained with 

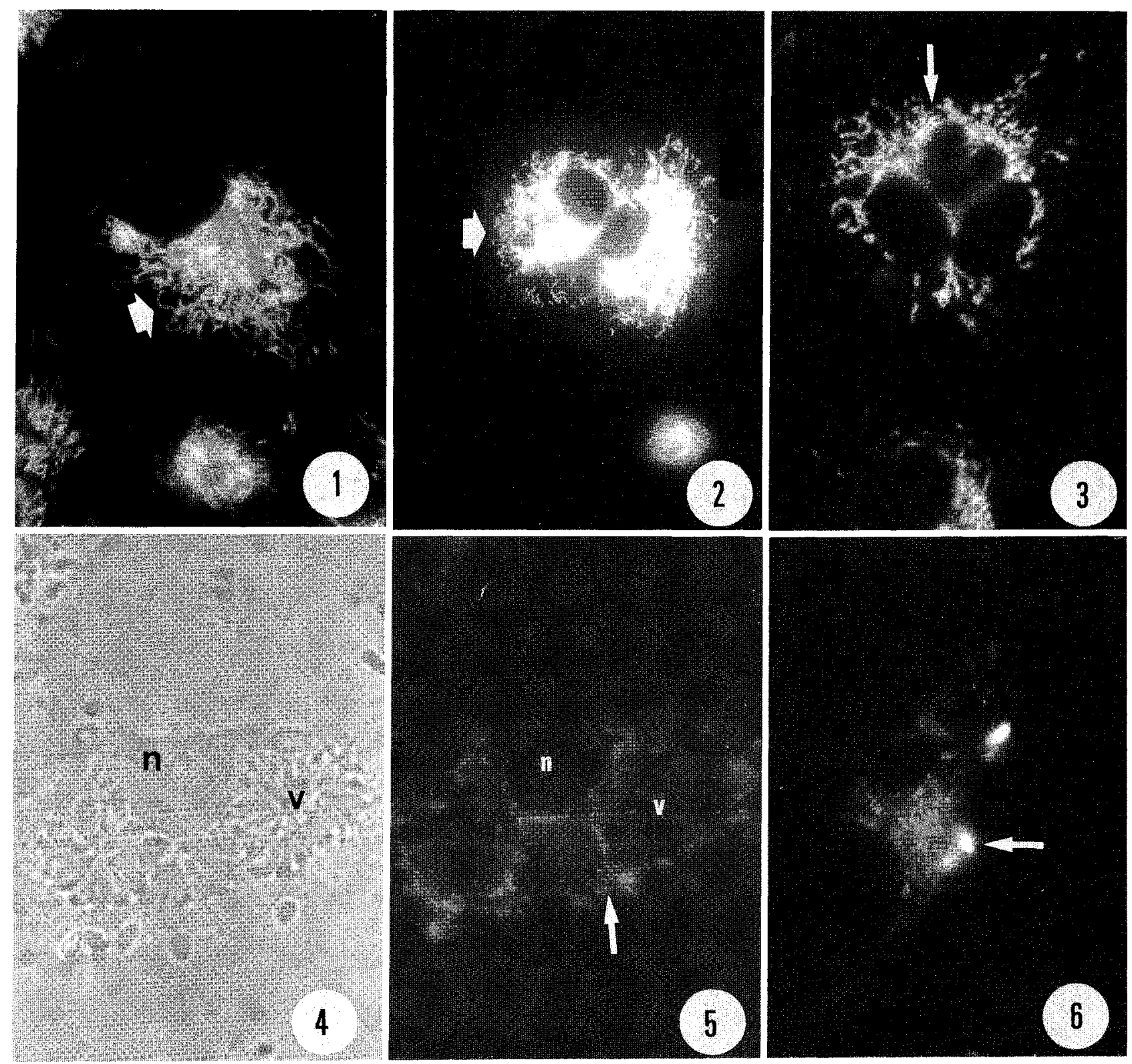

Figs. 1-6. Living Vero cells labeled with rhodamine 123 and examined by fluorescence microscopy (Figs. 3-5, 5-6) or phase contrast microscopy (Fig. 4). Control cells (Figs. 1-2) show large filamentous mitochondria radiating from the perinuclear region toward the periphery (arrow). Cell infected with tachyzoites of $T$. gondii shows mitochondria concentrated around the parasitophorous vacuole and the nucleus (arrows in Figs. 3, 5). Note that after longer infection time, only short mitochondria are seen (Figs. 3-5). Figures 4 and 5 show the same cells in phase contrast and fluorescence microscopy, respectively. Parasites adhering to the cell are labeled (arrow in Fig. 6), while intracellular parasites are not labeled. Figs. 1-3: $\times 750$; Figs. 4-5: $\times 1,020$; Fig. 6: $\times 680$. n, nucleus; v, parasitophorous vacuole.

C6-NBD-ceramide appeared as a bright compact structure located at one side of the nucleus (Fig. 14). This staining pattern was not modified by the parasites (Figs. 15-16).

Electron microscopy. Thin sections of cells receminfected with the parasites showed the tendency of the mitochondria to concentrate around the parasitophor- ous vacuole, which is aligned by a typical membrane (Fig. 17). After 24 hours, some cisternae of the rough endoplasmic reticulum also concentrate around the parasitophorous vacuole (Fig. 18). The smooth portion of the reticulum establishes a close contact with the vacuole in such a way that in some sections it is aligned with the membrane of the parasitophorous vacuole (Fig. 18). 

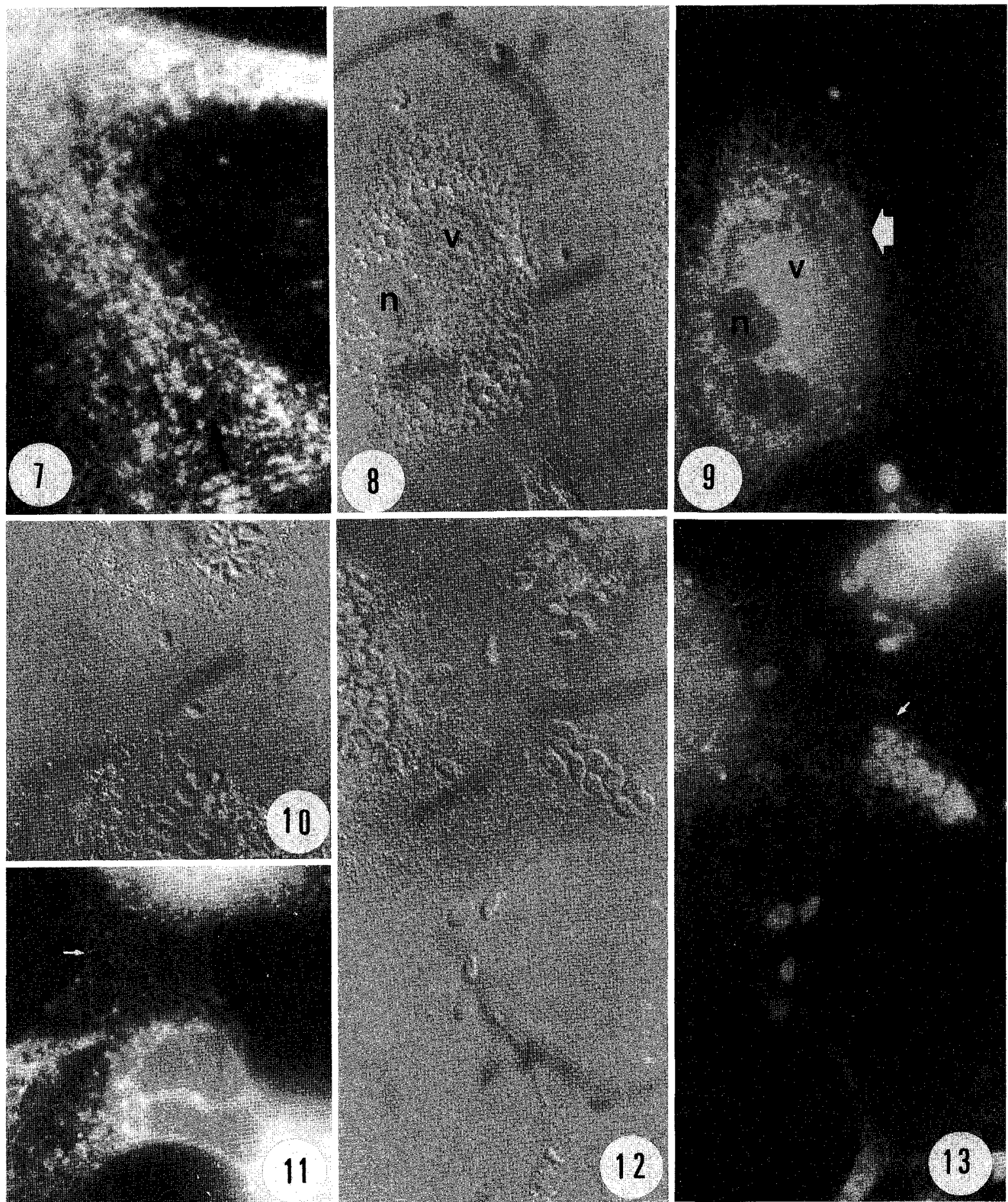

Figs. 7-13. Glutaraldehyde-fixed Vero cells labeled with DiOC6 to show the organization of the endoplasmic reticulum. A high fluorescence is observed around the nucleus, showing a punctuated pattern (Fig. 7). At the periphery of the cell we can see a reticulated aspect (arrow). Figures $8-9,10-11$, and 12-13 show the same field in phase contrast and fluorescence microscopy. Infection of the cells with $T$. gondii does not interfere with the general pattern of staining (arrow), although in some cases the reticulated aspect of the infected cells is more evident (small arrow in Figs. 10-11). Extracellular as well as intracellular parasites are labeled (Figs. 12-13). The membrane lining the parasitophorous vacuole is also labeled (small arrow in Fig. 13). Fig. 7: $\times 1,200$; Fig. 8-9, 12-13: $\times 680$; Figs. 10-11: $\times 750 . v$, parasitophorous vacuole. 

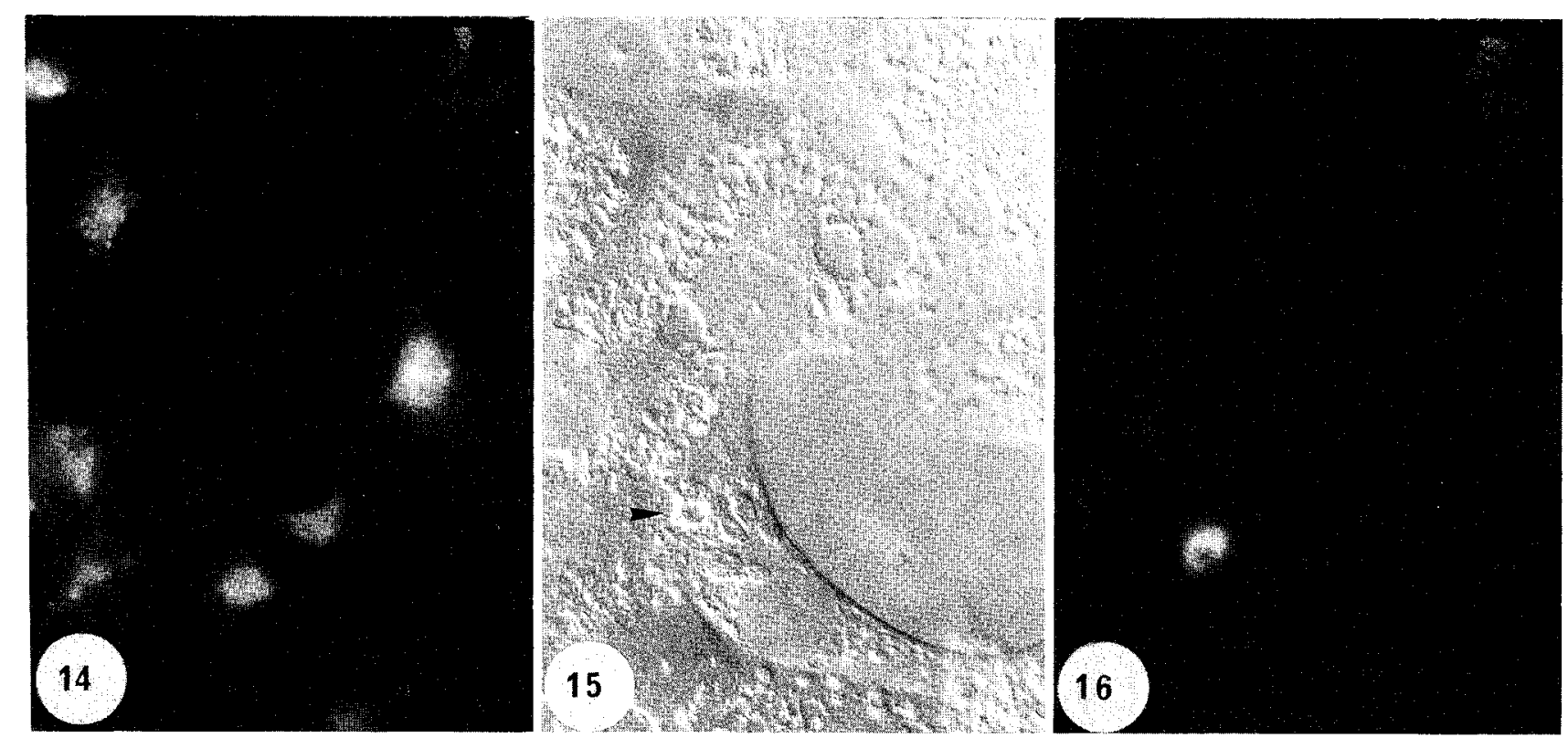

Figs. 14-16. Living Velo cells incubated with C6-NBD-ceramide to label the Golgi complex. Fluorescence is concentrated around the nucleus (Fig. 14). Figures 15 and 16 show the same field of infected cells in phase contrast and fluorescence microscopy, respectively. A bright compact structure located near the nucleus is observed (arrowheads in Figs. 15-16). $\quad \times 680$.

The Golgi complex was not modified, remaining close to the nucleus.

\section{DISCUSSION}

In the last few years a significant number of research groups have analyzed, in some detail, the process of interaction of intracellular parasites such as Plasmodium (14), Leishmania (3), Trypanosoma cruzi (1) and T. gondii (7) with their host cells. In most of these studies, however, the main focus of attention has been the parasite-host cell recognition process. There are very few studies analyzing the changes induced by the parasite in the structural organization of the host cell, and those existent deal with the interaction of host cell lysosomes with the parasite-containing vacuoles, the so-called parasitophorous vacuoles.

Our present observations using rhodamine 123, which labels only functional mitochondria due to their membrane potential with negative interior charge maintained by proton pumps (5), show that the general form of the host cell mitochondria, as well as their spatial distribution, changes during evolution of the intracellular parasitism. In uninfected cells the mitochondria show in Vero cells a distribution similar to that reported in other cells where they appear as long filamentous structures radiating from the perinuclear region toward the cell periphery. Immediately after parasite penetration they appear as short structures which tend to concen- trate around the parasitophorous vacuole. At present there is no explanation for this change in the dimensions of the mitochondria. Although a quantitative study was not carried out, it was indicated that the intensity of fluorescence emitted by each cell was not affected by the presence of the parasites, suggesting that the activity of the host cell mitochondria is not affected by the parasites.

The tendency of the host cell mitochondria to concentrate around the parasitophorous vacuoles has been previously detected by electron microscopy (10) as well as by fluorescence microscopy (19). $T$. gondii seems to require ATP synthesized by the host cell mitochondria for its growth. Pfefferkorn and Schwartzman (16) showed that $T$. gondii incorporated exogeneous ATP, but they also noted that ATP was extensively degraded before entering the parasite. These authors also showed that $T$. gondii grow normally in cell mutants defective in aerobic respiration.

It is interesting to note that rhodamine 123 did not label the parasites located within the parasitophorous vacuole although it intensely labelled the extracellular parasites, including those attached to the host cell surface. In view of the fact that rhodamine 123 only stains functionally active mitochondria, this observation suggests that once within the parasitophorous vacuole the parasite mitochondria is no longer active. One possibility, which deserves further investigation, is that such inhibition of parasite mitochondrial activity is due to the sup- 


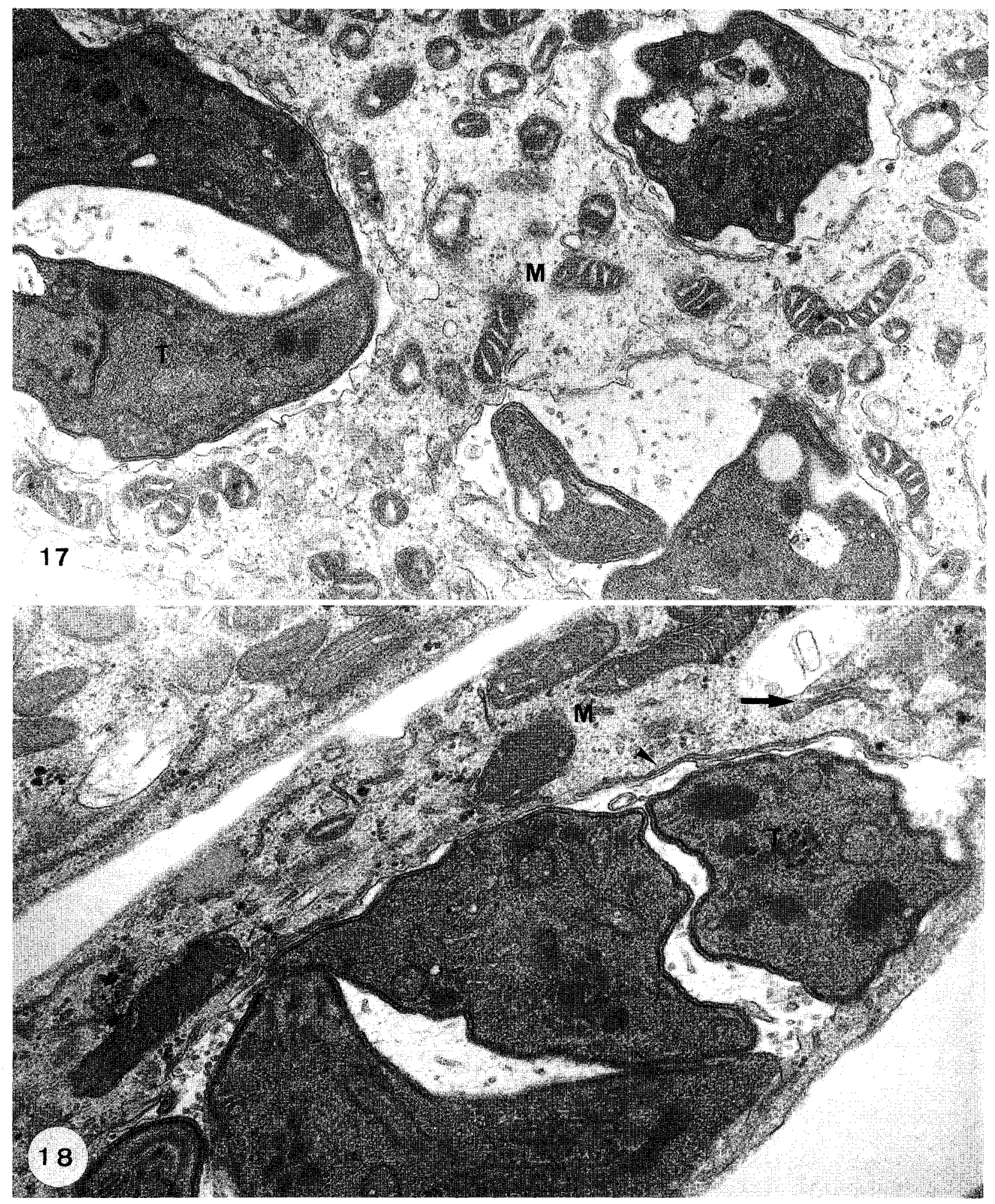

Figs. 17-18. Transmission electron microscopy of thin sections of Vero cells infected by $T$. gondii. In recem-infected cells (Fig. 17) the mitochondria $(\mathrm{m})$ concentrate around the parasitophorous vacuole containing tachyzoites of $T$. gondii. Later, elements of the endoplasmic reticulum (Fig. 18), especially of the smooth reticulum, concentrate around the parasitophorous vacuole, sometimes establishing a very close contact with its membrane (arrowheads). Fig. 17: $\times 10,500$; Fig. 18: 30,000. 
ply of mitochondrial metabolites by the host cell mitochondria.

Our observations using both fluorescence microscopy of DiOC6 stained cells, and transmission electron microscopy, show that elements of the smooth endoplasmic reticulum concentrate around, and even establish physical contact with, the membrane lining the parasitophorous vacuole. In several preparations it was clear that the membrane lining the parasitophorous vacuole was labeled. It is possible that labeling of this membrane is due to a simple partioning process, as described in other membranes (21). Another possibility is that this staining is due to the fact that portions of the endoplasmic reticulum fuse with the membrane lining the vacuole. This process would explain the fact that this membrane significantly grows during evolution of the intracellular parasitism when the vacuole increases in size. If this hypothesis is correct, the membrane lining the vacuole is indeed formed by (a) components of the plasma membrane of the host cell interiorized during parasite penetration, (b) components of the parasites, especially of the rhoptries, micronemes and dense bodies, which are liberated during and immediately after penetration (11) and (c) components of the smooth endoplasmic reticulum which fuse with the vacuolar membrane, with the evolution of the intracellular parasitism.

It is interesting to note that the parasite was also homogeneously stained with DioC6. However, observations made with electron microscopy do not show the presence of an exuberant endoplasmic reticulum in tachyzoites $(9,15)$. It is possible that the staining reflects interaction of DioC6 with the inner membrane complex of the parasite which is formed by two closely apposed unit membranes located immediately below the plasma membrane (4).

Acknowledgments. The authors thank Mr. Antonio de Oliveira for technical assistance and Miss Sandra Rocha for secretarial assistance. This work has been supported by Conselho Nacional de Desenvolvimento Científico e Tecnológico (CNPq) and Financiadora de Estudos e Projetos (FINEP).

\section{REFERENCES}

1. ARAUjo-Jorge, T.C. (1989). The biology of Trypanosoma cruzi-macrophage interaction. Mem. Inst. Oswaldo Cruz, 84: 441-462.

2. Aikawa, M., Komata, Y., and Mirorikawa, O. (1977). Transmission and scanning electron microscopy of host cell entry by Toxoplasma gondii. An J. Pathol., 87: 285-296.

3. Chang, K.P. (1990). Cell Biology of Leishmania. In Modern Parasite Biology (D.J. Wyler, ed.). New York, W.H. Freeman and Company, pp. 79-90.

4. Cintra, W.M. and De Souza, W. (1985). Distribution of intramembranous particles and filipin-sterol complexes in the cell membranes of Toxoplasma gondii. Eur. J. Cell Biol., 37: 6369.
5. JONHSON, L.V., WALSH, M.L., and CHEN, L.B. (1980). Localization of mitochondria in living cells with rhodamine 123. Proc. Natl. Acad. Sci. U.S.A., 77: 990-994.

6. Johnson, L.V., WALsh, M.L., Bockus, B.J., and Chen, L.B. (1981). Monitoring of relative mitochondrial membrane potential in living cells by fluorescence microscopy. $J$. Cell Biol., 88: 526-535.

7. Jones, T.C., YeH, S., and Hirsch, J.G. (1972). The interaction between Toxoplasma gondii and mammalian cells. J. Exp. Med., 136: 1157-1172.

8. LeE, C. and Chen, L.B. (1988). Dynamic behavior of endoplasmic reticulum in living cells. Cell, 54: 37-46.

9. MCLEOD, R., MACK, D., and Brown, C. (1991). Toxoplasma gondii New advances in cellular and molecular biology. Experimental Parasitol., 72: 109-121.

10. Melo, E.J.T., Carvalho, T.U., and De Souza, W. (1990). Monitoring the influence of multiplication of Toxoplasma gondii on the organization of mitochondria in Vero cell line using rhodamine 123 and electron microscopy. Mem. Inst. Oswaldo Cruz, 85 (suppl. I): 145.

11. Nichols, B.A., Chiappino, M.L.; and O'Connor, G.R. (1983). Secretion from the rhoptries of Toxoplasma gondii during host-cell invasion. J. Ultrastruct. Res., 83: 85-98.

12. Nichols, B.A. and O'ConNoR, G.R. (1981). Penetration of mouse peritoneal macrophages by the Protozoan Toxoplasma gondii. Lab. Invest., 44: 324-335.

13. Pagano, R.E., Sepanski, M.A., and Martin, O.C. (1989). Molecular trapping of a fluorescent ceramide analogue at the Golgi apparatus of fixed cells: interaction with endogenous lipids provides a trans-Golgi marker for both light and electron microscopy. J. Cell Biol., 109: 2067-2079.

14. Perkins, M.E. (1990). Cell Biology of Plasmodium. In Modern Parasite Biology, (D.J. Wyler, ed.). New York, W.H. Freeman and Company, pp. 5-25.

15. Pfefferkorn, E.R. (1990). Cell Biology of Toxoplasma gondii. In Modern Parasite Biology (D.J. Wyler, ed.). New York, W.H. Freeman and Company, pp. 26-50.

16. PfeFferkorn, E.R. and Schwartzmann, J.D. (1981). Use of mutants to study the biochemistry of the host-parasite relationship in cultured cells infected with Toxoplasma gondii. In International Cell Biology (H.G. Schweiger, ed.). Springer Verlag, 411-420.

17. Sibley, L.D. (1989). Active modification of host cell phagosomes by Toxoplasma gondii. In Intracellular Parasitism (J.W. Moulder, ed.). CRS Press. Inc., 1: 246-255.

18. Silva, S.R.L., Meirelles, S.S.L., and De Souza, W. (1982). Mechanism of entry of Toxoplasma gondii into vertebrate cells. J. Submicrosc. Cytol., 14: 471-482.

19. TANABE, K. (1985). Visualization of the mitochondria of Toxoplasma gondii-infected mouse fibroblast by the cationic permeant fluorescent dye rhodamine 123. Experientia, 41: 101-102.

20. Terasaki, M., Song, J., Wong, J.R., Weiss, M.J., and Chen, L.B. (1984). Localization of endoplasmic reticulum in living and glutaraldehyde-fixed cells with fluorescent dyes. Cell, 38: 101-108.

21. Terasaki, M. (1989). Fluorescent labeling of endoplasmic reticulum. In Fluorescence Microscopy of Living Cells in Culture (Y. Wang, and D.L. Taylor, eds.). Meth. Cell Biol., 29: 125136.

(Received for publication, May 7, 1992 and in revised form, September 9, 1992) 